\title{
A Systematic Review of the Economic Evaluation of Telemedicine in Japan
}

\section{Miki Akiyama', Byung-Kwang Yoo²}

${ }^{1}$ Faculty of Environment and Information Studies, Keio University, Kanagawa, Japan; ${ }^{2}$ Department of Public Health Sciences, University of California, Davis, School of Medicine, Davis, CA, USA

Objectives: There is no systematic review on economic evaluations of telemedicine in Japan, despite over 1000 trials implemented. Our systematic review aims to examine whether Japan's telemedicine is cost-saving or cost-effective, examine the methodological rigorousness of the economic evaluations, and discuss future studies needed to improve telemedicine's financial sustainability.

Methods: We searched five databases, including two Japanese databases, to find peer-reviewed articles published between January 1 , 2000 and December 31, 2014 in English and Japanese that performed economic evaluations of Japan's telemedicine programs. The methodological rigorousness of the economic analyses was assessed with a well-established checklist. We calculated the benefit-to-cost ratio $(B C R)$ when a reviewed study reported related data but did not report the BCR. All cost values were adjusted to 2014 US dollars.

Results: Among the 17 articles identified, six studies reported on settings connecting physicians for specialist consultations, and eleven studies on settings connecting healthcare providers and patients at home. There are three cost-benefit analyses and three costminimization analyses. The remaining studies measured the benefit of telemedicine only, using medical expenditure saved or users' willingness-to-pay. There was substantial diversity in the methodological rigorousness. Studies on teledermatology and teleradiology indicated a favorable level of economic efficiency. Studies on telehomecare gave mixed results. One cost-benefit analysis on telehomecare indicated a low economic efficiency, partly due to public subsidy rules, e.g., a too short budget period.

Conclusions: Overall, telemedicine programs in Japan were indicated to have a favorable level of economic efficiency. However, the scarcity of the economic literature indicates the need for further rigorous economic evaluation studies.

Key words: Telemedicine, Telehealth, Economic evaluation , Cost-benefit analysis

\section{INTRODUCTION}

Received: May 4, 2016 Accepted: June 22, 2016

Corresponding author: Byung-Kwang Yoo, MD, PhD

One Shields Ave., Medical Sciences 1C, Davis, CA 95616, USA

Tel: +1-530-752-6375, Fax: +1-530-752-3239

E-mail: byoo@ucdavis.edu

This is an Open Access article distributed under the terms of the Creative Commons Attribution Non-Commercial License (http://creativecommons.org/licenses/by$\mathrm{nc} / 4.0 /$ ) which permits unrestricted non-commercial use, distribution, and reproduction in any medium, provided the original work is properly cited.
Telemedicine, broadly defined as the use of medical information exchanged from one site to another via electronic communications to improve a patient's clinical health status [1], has been expected to improve simultaneously the cost of, quality of, and access to healthcare. There are over 80 systematic reviews on the effectiveness of telemedicine and more than 20 of them reporting conclusively that telemedicine is effective [2] in such areas as mental health [3-5] and management of chronic diseases [6-8] including diabetes, heart failure, and elderly care $[9,10]$. 
However, previous systematic reviews on the economic evaluation of telemedicine, based on study populations in the US, the UK, and Australia, show there is no conclusive evidence that telemedicine interventions are cost-saving or costeffective compared to conventional health care [11-14]. In many countries, it has been reported that a large number of telemedicine programs have been started on a trial basis but discontinued for larger scale implementation due to lack of sustainable financial sources [15-19]. This is mainly because most insurers do not reimburse new types of healthcare delivery [20-22]. For this reason, several studies have stated that comprehensive cost-effectiveness studies are essential in justifying insurer coverage and reimbursement for telemedicine in the future $[23,24]$.

Japan has faced a growing proportion of elderly people amidst a declining overall population. In 2014, the proportion of the population aged 65 or older was estimated to be $25.9 \%$ - the highest proportion in the world [25]. Currently, two major healthcare issues in Japan are the increasing total cost of healthcare and the uneven distribution of healthcare resources. The latter issue limits the access of remotely located people to sufficient healthcare services. Telemedicine is deemed to be a potential solution for these current twofold issues.

Based on the budget records issued by Japan's Ministry of Finance, we calculated public expenditure for development and pilot trials of health information technology, including telemedicine, from 2008 to 2014 -the result was $\$ 1.5$ billion. Despite such enormous amounts in public subsidies for telemedicine, the literature indicated serious concern about the financial sustainability of telemedicine $[26,27]$.

Among the studies reporting the effectiveness of telemedicine experiments around the country, only a small subset of these studies conducted an economic evaluation. The absence of a cohesive body of rigorous economic evaluation studies may be one of the key obstacles to the widespread adoption, proliferation, and funding of telemedicine programs [9,28-30].

This study's aim was to conduct a systematic review to identify and analyze the published economic evaluations on telemedicine in Japan. This qualitative assessment has three objectives: (a) to identify whether, and in what areas, telemedicine was evaluated to achieve a favorable level of economic efficiency, that is, whether it was cost-saving or cost-effective in Japan; (b) to assess the methodological rigorousness of the economic evaluations; and (c) to discuss future studies neces- sary to improve the general financial sustainability of telemedicine.

\section{METHODS}

This article focuses on telemedicine in broader health areas to make the results more comprehensive. Specifically, this study gathered economic evaluations of telemedicine connecting "non-specialized physicians and specialized physicians," "physicians and patients," and "public health nurses and patients."

\section{Search Strategy}

We searched the following databases: PubMed/MEDLINE, Web of Science, IEEE Xplore, Ichushi-Web database (the largest Japanese health database), and CiNii Articles (the largest Japanese database in all academic fields). All peer-reviewed articles published between January 1, 2000 and December 31, 2014 in English and Japanese were selected if they included any type of economic evaluation in monetary terms.

The inclusion criteria regarding economic evaluation were full economic evaluation [31] (i.e., cost-minimization analysis [CMA], cost-effectiveness analysis [CEA], cost-utility analysis [CUA], cost-benefit analysis [CBA]), cost-only analysis, or benefit-only analysis. The exclusion criteria were articles that described only effectiveness or benefit in non-monetary terms and articles available only in abstract form. Table 1 shows the different and exact combinations of keywords, relating to economic evaluation and telemedicine, used in this research. We used comparable Japanese words for Japanese databases.

\section{Review Process}

The selection process for the articles involved reading the titles and abstracts of the results obtained by one of the authors. After duplicate articles were deleted, all abstracts were read for relevance based on the inclusion and exclusion criteria. The relevant full-text articles were then obtained and thoroughly read by two authors. A classification of the telemedicine types, economic-analysis types, study designs, study populations, time frames, and the selection for the final appraisal were obtained by reading both the abstracts and the entire articles. In case of any disagreement, the two authors discussed the article and one designated author made the final decision.

In order to compare a variety of studies conducted in different time periods, we made a purchasing power parity adjust- 
Table 1. Search strategy

\begin{tabular}{|c|c|}
\hline Database $^{1}$ & Keywords for search \\
\hline PubMed/MEDLINE & $\begin{array}{l}\text { ("costs and cost analysis"[MeSH terms] OR "cost benefit analysis"[MeSH terms] OR "cost effectiveness" OR "cost utility") AND } \\
\text { ("telemedicine"[MeSH terms] OR telecare OR telehealth OR e-health) AND Japan }\end{array}$ \\
\hline Web of Science & $\begin{array}{l}\text { TS }=\left(" \text { cost } \$ \text { analysis" OR "cost* benefit" OR "cost }{ }^{*} \text { effectiveness" OR "cost }{ }^{*} \text { utility" OR "economic evaluation") AND TS=(telemedicine }\right. \\
\text { OR tele*care OR tele*health OR e*health) AND TS }=\left(\text { Japan* }^{*}\right)\end{array}$ \\
\hline IEEE Xplore & $\begin{array}{l}\text { ("cost analysis" OR "cost benefit" OR "cost effectiveness" OR "cost utility" OR "economic evaluation") AND (telemedicine OR telec } \\
\text { are OR telehealth OR e-health) AND Japan }\end{array}$ \\
\hline Ichushi-Web² & $\begin{array}{l}\text { (in Japanese) Within "Original Article" category, used ("cost analysis" OR "cost benefit" OR "cost effectiveness" OR "cost utility" OR } \\
\text { "economic evaluation") AND (telemedicine OR telecare OR telehealth OR e-health) }\end{array}$ \\
\hline CiNii Articles ${ }^{2}$ & $\begin{array}{l}\text { (in Japanese) ("cost analysis" OR "cost benefit" OR "cost effectiveness" OR "cost utility" OR "economic evaluation") AND } \\
\text { (telemedicine OR telecare OR telehealth OR e-health) }\end{array}$ \\
\hline
\end{tabular}

${ }^{1}$ The index period was 2000-2014 except for IEEE Xplore, which only allowed a search of journals published after 2002.

${ }^{2}$ For Japanese databases, relevant keywords were used, and the word "Japan" was not used.

ment and converted all costs to 2014 US dollars using the consumer price index [25].

\section{Economic Evaluation Quality Assessment}

We critically assessed the methodological rigorousness of the economic evaluation for each article based on the latest version of the checklist developed by Drummond et al. [31]. This checklist was chosen partly because it was one of the most widely used assessment tools in this area, e.g., this checklist's older version was known and widely used as "the BMJ Check-List" [32,33]. The most recent version of this checklist, published in 2015 [31], contains 87 items under ten headings (detailed in Table 2). Assessors are asked to check either "yes," "no," or "not applicable" (N/A) for each of ten subheadings according to the relative importance subjectively conferred to each item under each subheading. There is no explicit weighting for each item to calculate a single aggregated score. This checklist concentrates on full economic evaluations, but could also be used for partial economic evaluations, reports, and commentaries on economic evaluations. If items were not applicable to a specific study, a "N/A" response could be used.

Miki Akiyama and Byung-Kwang Yoo graded three studies using the criteria in order to reach consensus on the interpretation of the criteria, and Miki Akiyama graded the remaining papers.

\section{Supplemental Estimation Based on Published Data}

When a reviewed study reported cost and benefit but did not report the benefit-to-cost ratio (BCR) [34-36], we made a supplemental estimation of $B C R$ by dividing the reported financial benefit by the reported cost [31]. The financial benefit

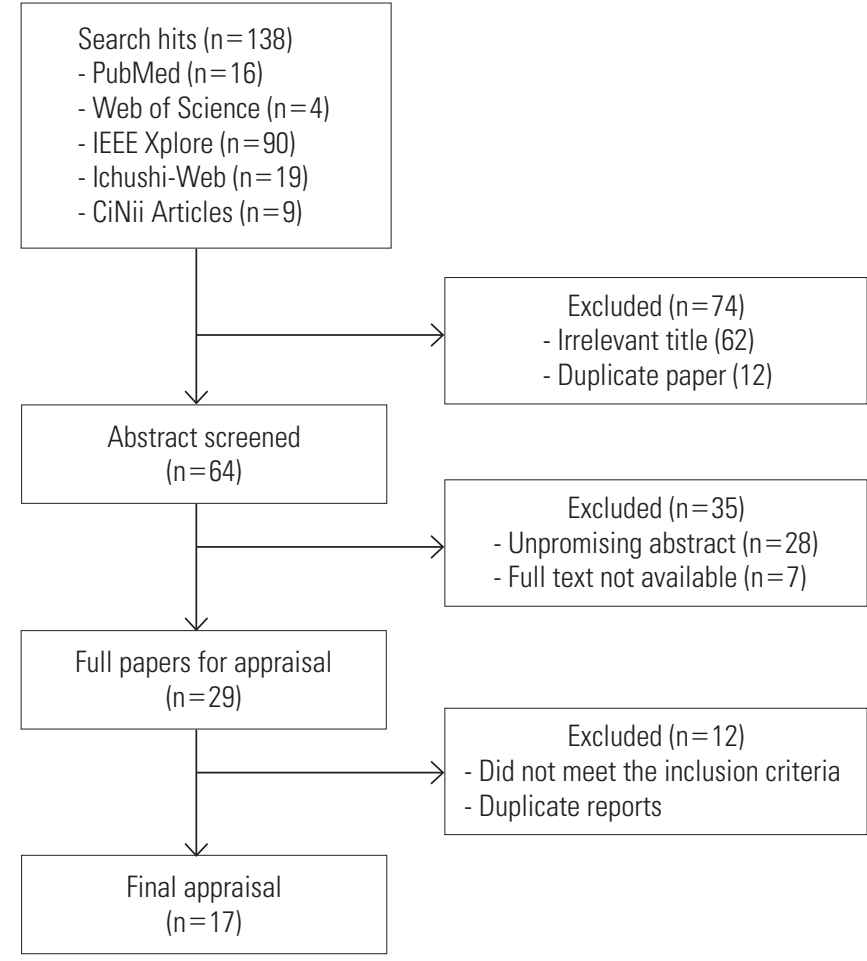

Figure 1. Flowchart of the steps followed in this review.

was estimated as the reduced medical care expenditure without assigning any monetary value for an improvement in health outcome.

\section{RESULTS}

\section{Summary of Identified Literature}

Figure 1 shows a flowchart with the steps followed in this review. The initial screening of the electronic databases retrieved 138 titles and abstracts; after the removal of duplicates 


\section{Contain items}

\section{Was a well-defined question posed in answerable form?}

1.1. Did the study examine both costs and effects of the service(s) or programme(s) over an appropriate time horizon?

1.2. Did the study involve a comparison of alternatives?

1.3. Was a viewpoint for the analysis stated and was the study placed in any particular decision-making context?

1.4. Where the patient population and any relevant subgroups adequately defined?

2. Was a comprehensive description of the competing alternatives given (i.e. can you tell who did what to whom, where, and how often)?

2.1. Were there any important alternatives omitted?

2.2. Was (should) a do-nothing alternative (be) considered?

2.3. Were relevant alternatives identified for the patient subgroups?

3. Was the effectiveness of the programme or services established?

3.1. Was this done through a randomised, controlled clinical trial? If so, did the trial protocol reflect what would happen in regular practice?

3.2. Was effectiveness established through an overview of clinical studies? If so, were the search strategy and rules for inclusion or exclusion outlined?

3.3. Were observational data or assumptions used to establish effectiveness? If so, were any potential biases recognized?

4. Were all the important and relevant costs and consequences for each alternative identified?

4.1. Was the range wide enough for the research question at hand?

4.2. Did it cover all relevant viewpoints? (Possible viewpoints include the community or social viewpoint, and those of patients and third-party payers. Other viewpoints may also be relevant depending upon the particular analysis.)

4.3. Were the capital costs, as well as operating costs, included?

5. Were costs and consequences measured accurately in appropriate physical units (e.g. hours of nursing time, number of physician visits, lost work-days, gained life years)?

5.1. Were the sources of resource utilization described and justified?

5.2. Were any of the identified items omitted from measurement? If so, does this mean that they carried no weight in the subsequent analysis?

5.3. Were there any special circumstances (e.g., joint use of resources) that made measurement difficult? Were these circumstances handled appropriately?

6 . Were the cost and consequences valued credibly?

6.1. Were the sources of all values clearly identified? (Possible sources include market values, patient or client preferences and views, policy-makers' views and health professionals' judgements)

6.2. Were market values employed for changes involving resources gained or depleted?

6.3. Where market values were absent (e.g. volunteer labour), or market values did not reflect actual values (such as clinic space donated at a reduced rate), were adjustments made to approximate market values?

6.4. Was the valuation of consequences appropriate for the question posed (i.e. has the appropriate type or types of analysis - cost-effectiveness, cost-benefit, cost-utility been selected)?

7. Were costs and consequences adjusted for differential timing?

7.1. Were costs and consequences that occur in the future 'discounted' to their present values?

7.2. Was there any justification given for the discount rate used?

8. Was an incremental analysis of costs and consequences of alternatives performed?

8.1. Were the additional (incremental) costs generated by one alternative over another compared to the additional effects, benefits, or utilities generated?

9. Was allowance made for uncertainty in the estimates of costs and consequences?

9.1. If patient-level data on costs or consequences were available, were appropriate statistical analyses performed?

9.2. If a sensitivity analysis was employed, was justification provided for the form(s) of sensitivity analysis employed and the ranges or distributions of values (for key study parameters)?

9.3. Were the conclusions of the study sensitive to the uncertainty in the results, as quantified by the statistical and/or sensitivity analysis?

9.4. Was heterogeneity in the patient population recognized, for example by presenting study results for relevant subgroups?

10. Did the presentation and discussion of study results include all issues of concern to users?

10.1. Were the conclusions of the analysis based on some overall index or ratio of costs to consequences (e.g. cost-effectiveness ratio)? If so, was the index interpreted intelligently or in a mechanistic fashion?

10.2. Were the results compared with those of others who have investigated the same question? If so, were allowances made for potential differences in study methodology?

10.3. Did the study discuss the generalisability of the results to other settings and patient/client groups?

10.4. Did the study allude to, or take account of, other important factors in the choice or decision under consideration (e.g. distribution of costs and consequences, or relevant ethical issues)?

10.5. Did the study discuss issues of implementation, such as the feasibility of adopting the 'preferred' programme given existing financial or other constraints, and whether any freed resources could be redeployed to other worthwhile programmes?

10.6. Were the implications of uncertainty for decision-making, including the need for future research, explored?

"Assessors are asked to check either "yes," "no," or "not applicable" for each of the 10 subheadings according to the relative importance subjectively conferred to each item under each subheading. 
and irrelevant titles, 64 abstracts remained for screening and 29 potentially eligible full-text articles were obtained. We excluded 12 articles after reading the full text, which were judged to meet the exclusion criteria. Two were general reviews of the situation in Asia, one was a review on the methodology of economic evaluation, four were benefit analyses using the same survey data, and five papers were not peer reviewed. Eventually, 17 peer-reviewed articles containing any form of economic appraisal in monetary terms remained.

Table 3 summarizes the characteristics and key findings of the selected studies. Among these studies, 12 were published in English [34-45] and five in Japanese [27,46-49]. The service settings of telemedicine were categorized into two major types: those connecting physicians for specialist consultations (the MD-MD setting) [34,35,37-39,49] and those connecting healthcare providers and patients [27,36,40-48], which were further sub-categorized into settings connecting physicians and patients at home (the MD-Patient setting), and those connecting public health nurses and patients at home (the PhNrs-Patient setting)

Clinical disciplines within MD-MD settings included dermatological consultation [35], pediatric medical consultation [49], emergency radiotherapy for malignant spinal cord compression [34], real-time computed tomography (CT) scan indication [37], teleradiology, and telepathology [38,39].

All of the 11 settings connecting healthcare providers and patients - that is, the MD-Patient setting and PhNrs-Patient setting - dealt with home-based systems with two types of functions. One function type is a stand-alone real-time video conference system for palliative care for cancer patients without continuous monitoring of vital signs [36]. The other type, evaluated by 10 articles [27,40-48], monitors vital signs with equipment such as an automated sphygmomanometer and a simple electrocardiograph for home. Healthcare providers contact a patient when an algorithm for monitored data detects an abnormal vital sign. This type of system targeted lifestyle-related diseases such as high blood pressure, diabetes, stroke, and heart failure among fragile elderly patients.

Regarding the types of economic evaluation, they were classified into four types; three were CBA $[34,40,48]$, which provide the most useful policy implication, that is, benefit measured by monetary value compared to input cost of telemedicine. Three studies were categorized as CMA [35-37], which estimate the cost reduction by telemedicine compared to a control group - both telemedicine and control groups achieved the same level of health outcome. Four studies [27,43-45] measured medical expenditure saved due to telemedicine, without calculating the input telemedicine cost or showing equal health outcomes. The remaining seven studies [38,39, $41,42,46,47,49]$ measured willingness-to-pay (WTP) for using telemedicine. There were no CEA or CUA studies.

\section{MD-MD Specialist Consultation}

Out of six studies of MD-MD settings, one clinical efficacy study presented detailed estimates of both the costs and benefits of telemedicine in emergency radiotherapy for malignant spinal cord compression (MSCC), connecting between a university hospital and 10 rural hospitals [34]. Since this study did not report the $B C R$, we calculated the ratios to range from 4.67 to 13.40 .

There were two CMA studies regarding MD-MD specialist live consultations. One CMA study on dermatology consultation [35] reported cost-saving of $\$ 330$ per person per week. This study's two-way sensitivity analysis indicated that the cost-saving results were sensitive to the two key parameters of travel time and consultation time. Assuming that travel time was 60 minutes and consultation time was five minutes (based on expert opinions from Japanese dermatologists), we calculated the $B C R$ to be 1.53 .

Another CMA study [37] examined teleradiology diagnosis accuracy in an MD-MD setting. This study estimated that teleconsultation contributed to cost-saving of $\$ 144$ per reading by avoiding unnecessary enhanced CT scans.

One survey [49] estimated the benefits of specialist teleconsultation in pediatric emergency care for primary care physicians in rural, underserved areas. These benefits were measured by inquiring about WTP among parents of children in two rural towns, that is, $\$ 31.40$ to $\$ 33.60$ per emergency department visit.

There were two studies conducted by one study group to estimate medical providers' WTP for teleradiology and telepathology $[38,39]$. These two studies applied different statistical methods for the same set of survey data obtained from healthcare providers across Japan, who used either teleradiology or telepathology in an MD-MD setting. Their WTP estimates were $\$ 489$ to $\$ 510$ for teleradiology and $\$ 1063$ to $\$ 1111$ for telepathology per person per year.

\section{Healthcare providers-patient homecare}

One CMA study [36] on home-palliative care in an MD-Pa- 


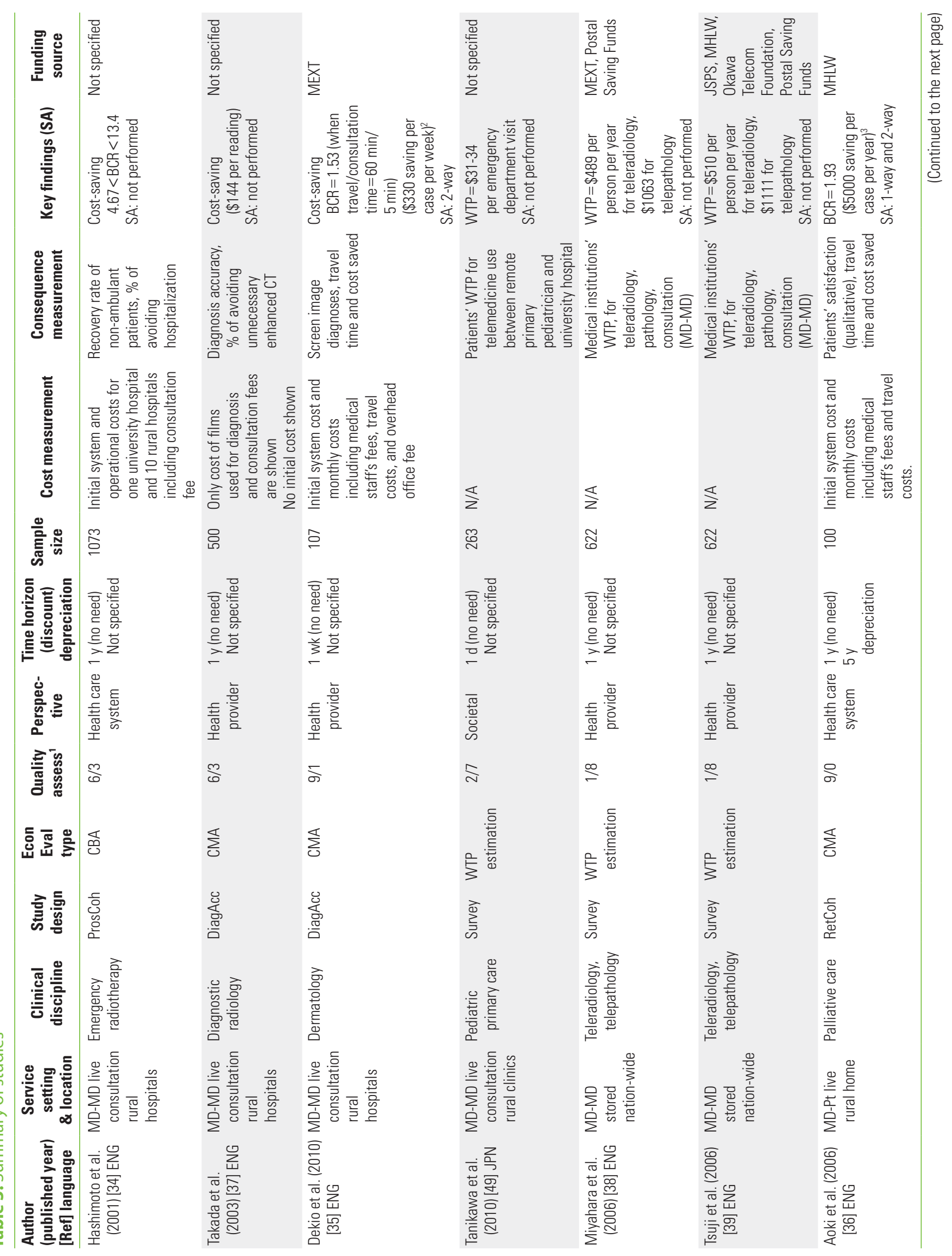




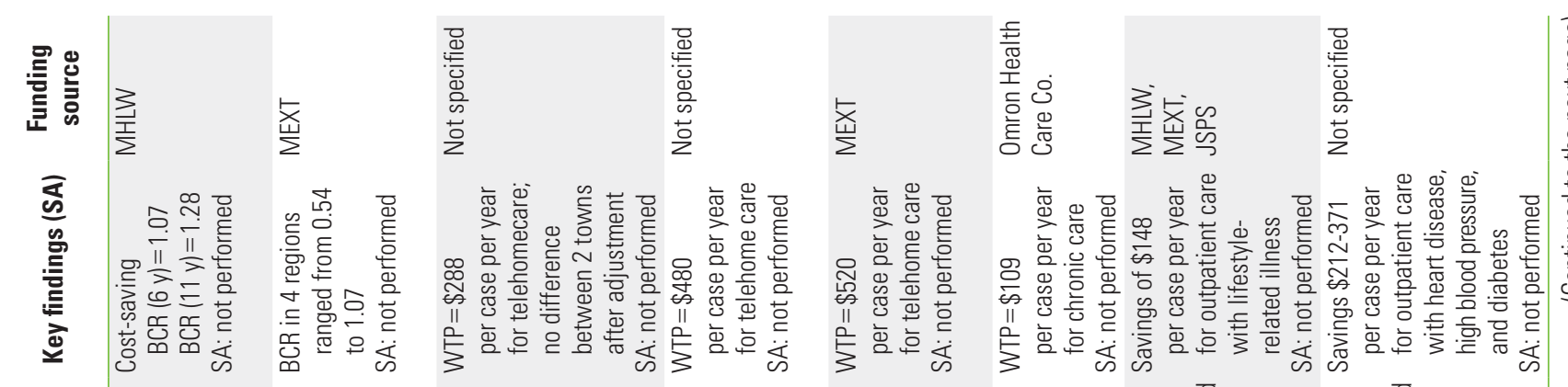

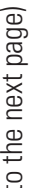
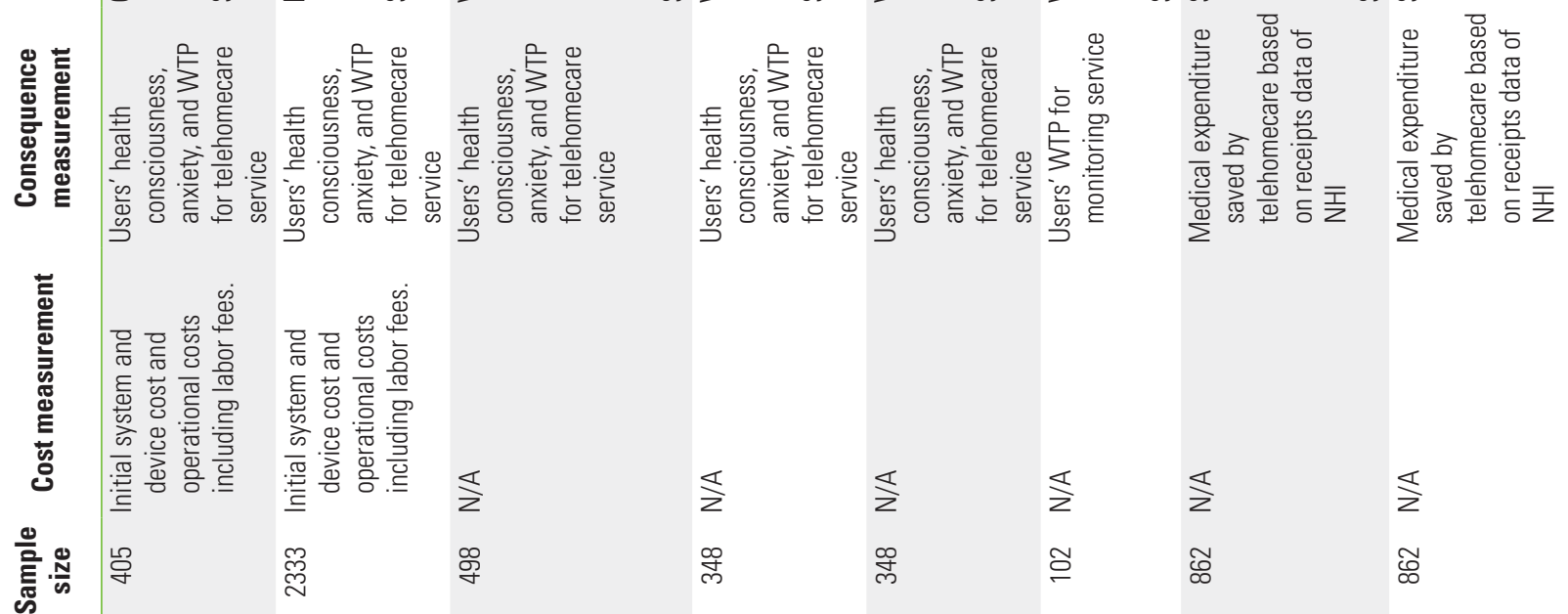

$\stackrel{1}{z}$

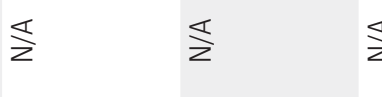

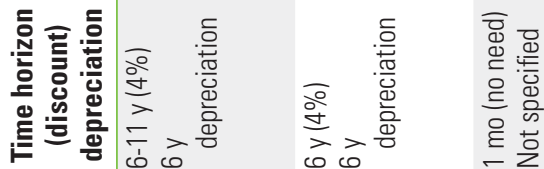

品

ले

ले

$\stackrel{\frac{1}{z}}{z}$

$\stackrel{\frac{\pi}{z}}{z}$
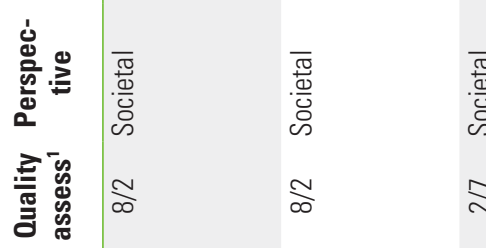

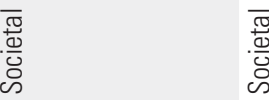
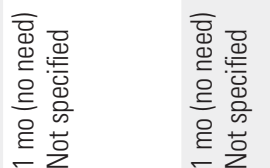

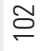

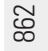

ॠ

$\stackrel{\infty}{\pi}$

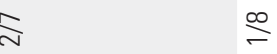

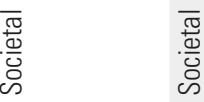

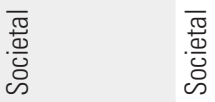

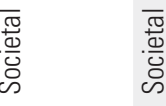

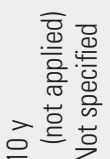

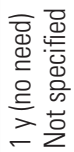

施

을 总

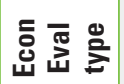

言焉

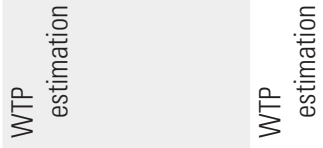

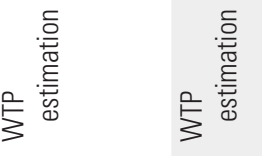

$\stackrel{\infty}{=}$

क्ष

.

$\stackrel{\infty}{=}$

항

$\stackrel{\infty}{m}$

จำ

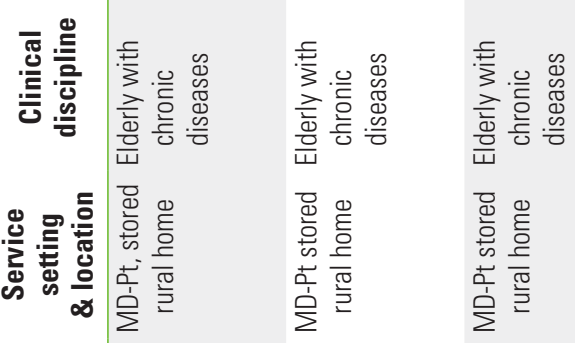

ले

齐

高离

莺.

ऐ)

仓

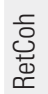

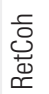
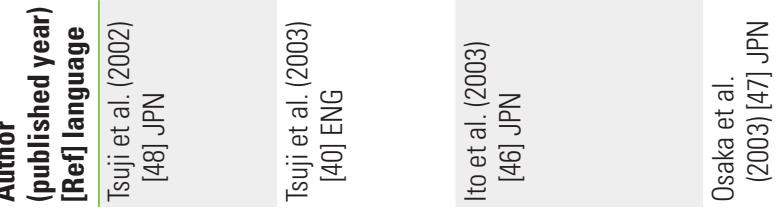

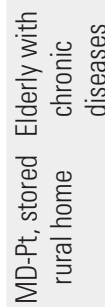

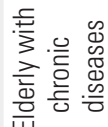

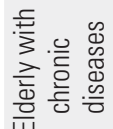

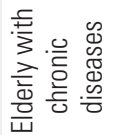

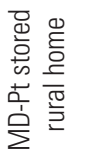

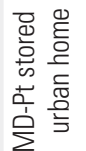

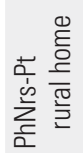

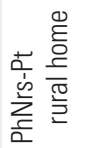

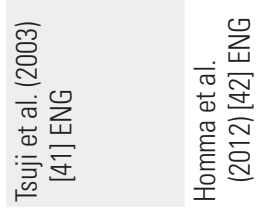

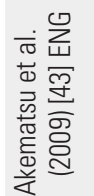

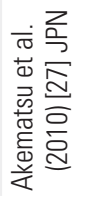



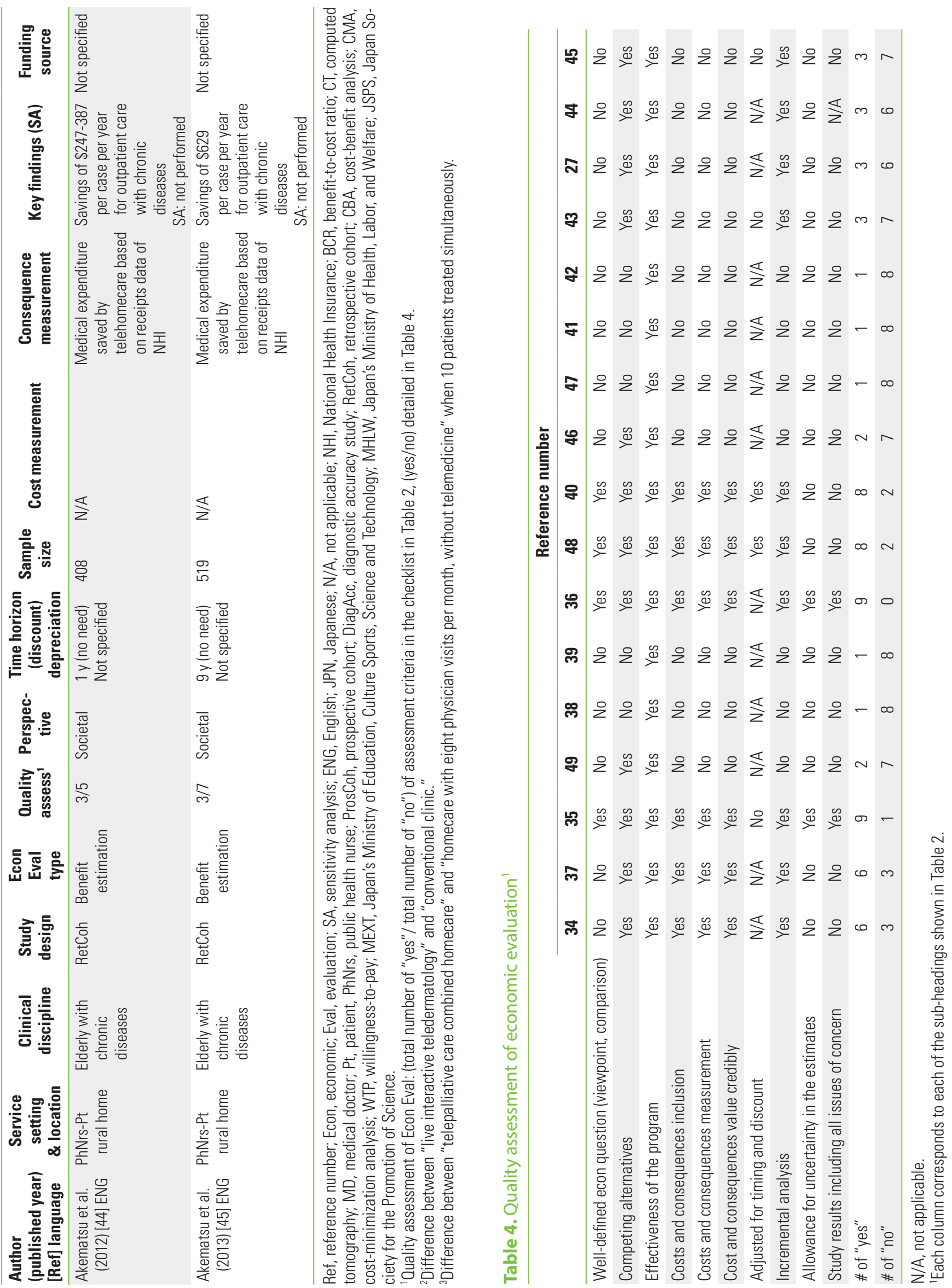
tient setting reported that telemedicine could reduce the frequency of physician visits from twice to once a week. The costsaving of home palliative care with telemedicine were estimated to be $\$ 5000$ per person per year compared to conventional home care. A sensitivity analysis of this study showed their results to be sensitive to two parameters, the number of user patients and duration of service provided. Based on the reported benefit, we calculated the BCR to be 1.93 .

One study group published two CBA studies on the same type of tele-homecare service operated in different regions with different financial schemes: (a) one region where a monthly fee was charged and (b) three other regions where no fee was charged because of public subsidies. Under the former scheme, the BCR was calculated to increase monotonically over time, that is, 1.07 (6-year operation) and 1.28 (11-year operation), using WTP estimates among patients in this region [48]. Under the latter scheme, the BCR estimates in the three regions ranged from 0.54 to 0.61 [40], indicating that telehomecare was not cost-saving.

There were four studies reporting medical expenditure saved by telehomecare connecting public health nurses and the elderly with chronic diseases in one region [27,43-45]. Based on the claims data, these studies showed that treatment periods were shortened by telemedicine. Their estimates of reduced medical expenditure ranged from $\$ 148$ to $\$ 629$ per case per year for lifestyle diseases [27,43-45]. However, the input costs of telehomecare were not shown in these four studies.

A single research team produced three survey studies and measured patients' WTP for a telehomecare system that combines vital-signs monitoring and doctor consultation. The WTP estimates were $\$ 288, \$ 480$, and $\$ 520$ per case per year, depending on three analytical methods $[41,46,47]$. There was only one study conducted in an urban area to estimate users' WTP for home tele-health monitoring. This study, published in 2012, showed WTP as low as $\$ 109$ per patient per year [42].

\section{Economic Evaluation Quality Assessment}

Table 4 summarizes our quality assessment of reviewed studies in terms of the ten criteria of the well-established checklist from Drummond et al. [31]. There were only four studies $[35,36,40,48]$ that met more than eight criteria, and eleven studies met only three or fewer criteria. Studies of CBA and CMA tended to meet more criteria than studies that measured only the benefits of telemedicine. Only two studies $[35,36]$ conducted a sensitivity analysis, and hence met the

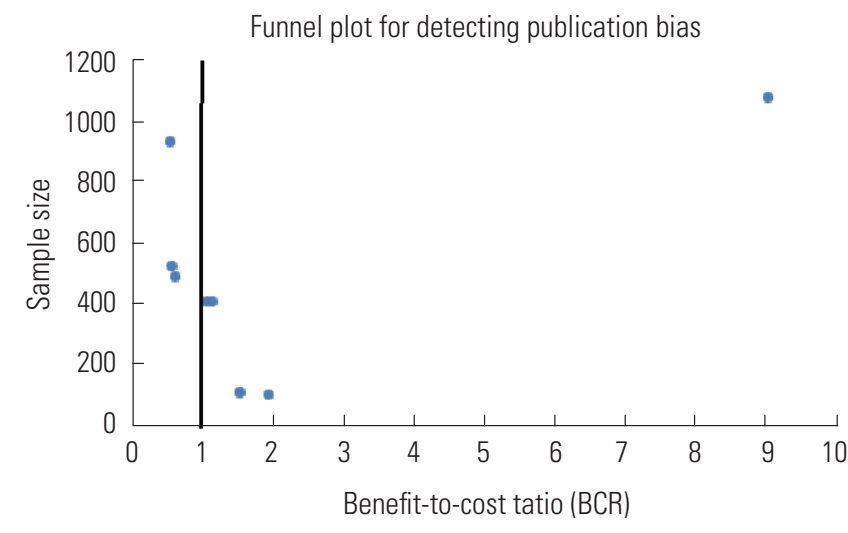

Figure 2. Funnel plot for detecting publication bias. A telehealth intervention is concluded to be cost-saving (i.e., economically efficient) when $\mathrm{BCR}$ (X-axis in the figure) exceeds one (represented by a bold vertical line in the figure). BCR takes on any non-negative value. A higher BCR value indicates a more economically efficient health intervention. For instance, the interpretation of BCR being two is that a $\$ 1$ investment in a telehealth intervention will generate a $\$ 2$ benefit. Due to the limited number of studies reporting BCR estimates, Figure 2 includes four plots of BCR estimates in four study sites in one publication [40]. When a reviewed paper did not report a single representive BCR estimate (e.g., mean), we calculated an average value of multiple BCR estimates.

two criteria of "uncertainty estimates" and "study results including all issues of concern."

\section{Publication bias}

Figure 2 was created to detect a potential publication bias among the reviewed papers. A bold vertical line in this figure represents a threshold $B C R$ value of one (also called a breakeven point). A plot located rightward of this threshold vertical line indicates a favorable economic efficiency level for a telehealth program evaluated in the published study. Since the plots were skewed to the right of the threshold vertical line (i.e., BCR greater than one), Figure 2 implies a moderate bias toward publishing more studies with a higher BCR estimate for a tele-health intervention. It should be noted that our interpretation regarding such potential publication bias has limited validity due to the small number of publications with $B C R$ estimates.

\section{DISCUSSION}

To our knowledge, this is the first systematic review to summarize the economic efficiency of Japanese telemedicine ser- 
vices and to examine the methodological rigorousness of the economic evaluation studies conducted in Japan. Despite the small number and the diverse quality of economic evaluations of telemedicine, most of these evaluations indicated a favorable level of economic efficiency, that is, net cost-saving, reduced medical expenditure, and/or positive WTP.

Among studies on MD-MD live consultations in hospital settings, the most economically efficient telemedicine was emergency radiotherapy consultation about malignant spinal cord compression [34]. This study's results were consistent with another effectiveness study of spinal cord compression in Canada [50], in terms of decreasing patient transfer and shortening treatment decision time. However, the robustness of the reported BCR magnitude ( $>4.67)$ is uncertain due to the absence of sensitivity analyses.

Another cost-saving form of telemedicine in an MD-MD hospital setting was teledermatology consultation (\$17 160 per case per year) [35]. This study addressed parameter uncertainty and indicated that whether teledermatology is cost-saving or not depends on the travel time and consultation time of physicians [35]. These results do not contradict the literature reporting mixed results; that is, teledermatology cost is either lower [51] or higher [52-55] than conventional care costs.

For an MD-Patient home setting, BCR of telemedicine-combination home palliative care was estimated to be 1.93 , compared to the status quo [36]. This CMA was methodologically rigorous with regard to (a) a clear statement of the purpose and perspective of the study, (b) a detailed illustration of the cost estimation, and (c) the implementation of a sensitivity analysis. This study in Japan is one of the few studies that explicitly indicated telemedicine to be cost-saving when used to supplement in-person home visits by physicians. Similar realtime, audio-visual communication services for home palliative care have been successfully used for some years in the US [56, 57] and Australia [58], while investigation in Canada [59] and pediatric telepalliative care in Australia [60] faced difficulties. In the US, the cost-saving of tele-palliative care was reported as due to a reduced number of home visits by nurses [56].

Regarding telehomecare among the elderly with chronic diseases, two CBAs reported cost-saving when implemented in one region (BCR, 1.07 to 1.28) $[40,48]$ where patients' WTP was the only outcome measured. These studies did not account for the potential reduced medical expenditure due to telemedicine. It should be noted that an identical system deployed in three other regions with public subsidies showed less economic efficiency (BCR $\leq 0.61)$ due to lower WTPs $(37 \%$ to $71 \%$ of the similar one-region system above) and higher system costs (186\% to $195 \%$ of the one-region system) [40]. The reason for the mixed $B C R$ results can be partly attributed to the public subsidy rule. The restrictive rules of public subsidy are exemplified by the prohibition on carrying over the budget to a second year [40], which may have caused over-utilization of the first year cost and hence ultimately decreased BCR.

The methodological rigorousness of the reviewed studies tended to deviate from the established guidelines for economic evaluations [31,32,61-63]. For instance, only five studies $[34-36,40,48]$ clarified the complete cost measurements of installing and operating telemedicine, which should have been compared with reduced medical expenditure due to the implementation of a telemedicine strategy such as a home telecare system (reduced by $\$ 148$ to $\$ 629$ per case per year) [27,4345] and teleradiology ( $\$ 144$ per CT reading) [37]. Therefore, other than these five studies, it seemed very difficult to determine the accurate economic efficiency level of telemedicine among the reviewed studies.

Moreover, none of the reviewed studies implemented a CEA or a CUA of the telemedicine program under focus. Therefore, it is impossible to judge whether a program is reasonably costeffective or not when it is not cost-saving.

Another example of a common limitation among the reviewed studies is the absence or very limited application of a probabilistic analysis such as a Monte Carlo simulation in order to address the uncertainty of multiple key parameters on cost, effectiveness, and benefit, simultaneously [31].

In addition to the small number of total publications on the topic in focus, there are even fewer studies that examined comparable types of telemedicine technology and outcomes. This limited number of studies prevented us from performing a quantitative summary of the literature, such as a meta-analysis.

We believe that the following types of future studies would be useful for an international audience as well as a Japanese one. To convince policymakers to initiate and continue public subsidies for telemedicine, researchers are expected to produce more methodologically rigorous empirical evidence, presented in a reader-friendly manner. The strongest evidence is to show cost-saving based on a CBA. Due to diverse costs and benefits depending on setting, a probabilistic analysis result is useful to report; for example, cost-saving is achieved by telemedicine in $57 \%$ of 5000 iterations in emergency departments [64] and $37 \%$ of 1000 iterations in intensive care units [65]. 
Moreover, hospital level administrators as well as policy-makers would find it easy to understand a concrete and realistic scenario; for example, treating 10 acutely ill and injured children at a rural emergency department with telemedicine will lead to annual cost-saving of $\$ 46620$ per emergency department [66]. These decision makers would also appreciate specific benchmarks to achieve cost-saving, such as maximum allowable cost derived from break-even analyses [65].

Since telemedicine in a probabilistic analysis is less likely to achieve cost-saving in 100\% of iterations, a CEA needs to be implemented to test whether telemedicine is reasonably costeffective or not [31]. To make CEA results of telemedicine comparable with other types of health care, a future study is expected to estimate an incremental cost-effectiveness ratio (ICER) with a unit of dollar value per additional quality-adjusted life year (QALY) by the US expert panel on cost-effectiveness in health and medicine [31,61-63]. A certain telemedicine care strategy is concluded to be cost-effective if its ICER is lower than a commonly used threshold of $\$ 100000$ per QALY [66]. These estimates concerning CEA are also appreciated by policymakers and insurers who are interested in maximizing health outcomes under a fixed budget.

Other than improving the methodological rigorousness of economic evaluations, our review demonstrated the importance of WTP measured among users and public subsidy rules. The measured WTP could be used as a proxy for a future user charge, which is particularly important if the WTP exceeds the actual out-of-pocket payment for telemedicine. Partly because of the difference in the surveyed populations, WTP for a similar health-monitoring telemedicine care strategy declined by 75 percentage points from 2003 to 2010 [42,47]. Potential reasons for the decline include the decreased Japanese purchasing power due to long-term macro-economic recession and users' observations of continuously falling prices in other IT products and services. Thus, further studies are needed in measuring WTP under various and detailed scenarios as well as addressing the impact of public subsidy regulation on BCR. These studies could help justify increased public financial support and hence improve the financial sustainability of telemedicine programs.

\section{CONCLUSION}

In conclusion, compared to the substantial resources deployed for more than 1000 telemedicine trials in Japan, very limited resources have been deployed for the economic evaluation of telemedicine trials. Although most reviewed economic evaluations reported a favorable level of economic efficien$c y$, their methodological rigorousness tended to vary. Further economic evaluation studies in this field are needed with more advanced methodological rigorousness and expanded research scope (e.g., public subsidy regulation impacts). These future studies are expected to help convince various decision makers such as policymakers, insurers and hospital administrators to invest further resources in telemedicine. Consequently, the general financial sustainability of telemedicine is expected to improve in the long term.

\section{ACKNOWLEDGEMENTS}

The authors would like to acknowledge Tomoko Sasaki, PhD, for her outstanding support with the literature search and editing.

\section{CONFLICT OF INTEREST}

The authors have no conflicts of interest associated with the material presented in this paper.

\section{ORCID}

Miki Akiyama http://orcid.org/0000-0002-3591-1475

Byung-Kwang Yoo http://orcid.org/0000-0001-6764-7130

\section{REFERENCES}

1. American Telemedicine Association. What is telemedicine? [cited 2015 Oct 30]. Available from: http://www.americantelemed.org/about-telemedicine/what-is-telemedicine\#.

2. Ekeland AG, Bowes A, Flottorp S. Effectiveness of telemedicine: a systematic review of reviews. Int J Med Inform 2010; 79(11):736-771.

3. Spek V, Cuijpers P, Nyklícek I, Riper H, Keyzer J, Pop V. Internetbased cognitive behaviour therapy for symptoms of depression and anxiety: a meta-analysis. Psychol Med 2007;37(3): 319-328.

4. Reger MA, Gahm GA. A meta-analysis of the effects of internet- and computer-based cognitive-behavioral treatments for anxiety. J Clin Psychol 2009;65(1):53-75.

5. Hyler SE, Gangure DP, Batchelder ST. Can telepsychiatry re- 
place in-person psychiatric assessments? A review and metaanalysis of comparison studies. CNS Spectr 2005;10(5):403413.

6. Polisena J, Tran K, Cimon K, Hutton B, McGill S, Palmer K, et al. Home telehealth for chronic obstructive pulmonary disease: a systematic review and meta-analysis. J Telemed Telecare 2010;16(3):120-127.

7. Gaikwad R, Warren J. The role of home-based information and communications technology interventions in chronic disease management: a systematic literature review. Health Informatics J 2009;15(2):122-146.

8. Martínez A, Everss E, Rojo-Alvarez JL, Figal DP, García-Alberola A. A systematic review of the literature on home monitoring for patients with heart failure. J Telemed Telecare 2006;12(5): 234-241.

9. Barlow J, Singh D, Bayer S, Curry R. A systematic review of the benefits of home telecare for frail elderly people and those with long-term conditions. J Telemed Telecare 2007;13(4): 172-179.

10. Demiris G, Hensel BK. Technologies for an aging society: a systematic review of "smart home" applications. Yearb Med Inform 2008:33-40.

11. Mistry H. Systematic review of studies of the cost-effectiveness of telemedicine and telecare. Changes in the economic evidence over twenty years. J Telemed Telecare 2012;18(1):16.

12. Mistry H, Garnvwa H, Oppong R. Critical appraisal of published systematic reviews assessing the cost-effectiveness of telemedicine studies. Telemed J E Health 2014;20(7):609-618.

13. Wade VA, Karnon J, Elshaug AG, Hiller JE. A systematic review of economic analyses of telehealth services using real time video communication. BMC Health Serv Res 2010;10:233.

14. de la Torre-Díez I, López-Coronado M, Vaca C, Aguado JS, de Castro C. Cost-utility and cost-effectiveness studies of telemedicine, electronic, and mobile health systems in the literature: a systematic review. Telemed J E Health 2015;21(2):8185.

15. Broens TH, Huis in't Veld RM, Vollenbroek-Hutten MM, Hermens HJ, van Halteren AT, Nieuwenhuis LJ. Determinants of successful telemedicine implementations: a literature study. J Telemed Telecare 2007;13(6):303-309.

16. Brebner JA, Brebner EM, Ruddick-Bracken H. Experiencebased guidelines for the implementation of telemedicine services. J Telemed Telecare 2005;11 Suppl 1:3-5.

17. Tinker A, Lansley P. Introducing assistive technology into the existing homes of older people: feasibility, acceptability, costs and outcomes. J Telemed Telecare 2005;11 Suppl 1:1-3.

18. Malasanos TH, Burlingame JB, Youngblade L, Patel BD, Muir AB. Improved access to subspecialist diabetes care by telemedicine: cost savings and care measures in the first two years of the FITE diabetes project. J Telemed Telecare 2005;11 Suppl 1:74-76.

19. Bratan T, Clarke M, Jones R, Larkworthy A, Paul R. Evaluation of the practical feasibility and acceptability of home monitoring in residential homes. J Telemed Telecare 2005;11 Suppl 1:29-31.

20. Aas IH, Geitung JT. Teleradiology and picture archiving and communications systems: changed pattern of communication between clinicians and radiologists. J Telemed Telecare 2005;11 Suppl 1:20-22.

21. Vitacca M, Mazzù M, Scalvini S. Socio-technical and organizational challenges to wider e-Health implementation. Chron Respir Dis 2009;6(2):91-97.

22. Kavamoto CA, Wen CL, Battistella LR, Böhm GM. A Brazilian model of distance education in physical medicine and rehabilitation based on videoconferencing and Internet learning. J Telemed Telecare 2005;11 Suppl 1:80-82.

23. Scalvini S, Capomolla S, Zanelli E, Benigno M, Domenighini D, Paletta $\mathrm{L}$, et al. Effect of home-based telecardiology on chronic heart failure: costs and outcomes. J Telemed Telecare 2005; 11 Suppl 1:16-18.

24. Vontetsianos T, Giovas P, Katsaras T, Rigopoulou A, Mpirmpa G, Giaboudakis $P$, et al. Telemedicine-assisted home support for patients with advanced chronic obstructive pulmonary disease: preliminary results after nine-month follow-up. J Telemed Telecare 2005;11 Suppl 1:86-88.

25. Statistics Bureau of Japan. Consumer price index (GL08 020103); 2015 [cited 2015 Dec 26]. Available from: http:// www.e-stat.go.jp/SG1/estat/List.do?bid $=000001033700 \&$ cycode $=0$ (Japanese).

26. Hasegawa T, Murase S. Distribution of telemedicine in Japan. Telemed J E Health 2007;13(6):695-702.

27. Akematsu Y, Tsuji M. Empirical analysis of home healthcare system and cost of four major life-related diseases. Jpn J Telemed Telecare 2010;6(2):171-174 (Japanese).

28. Dávalos ME, French MT, Burdick AE, Simmons SC. Economic evaluation of telemedicine: review of the literature and research guidelines for benefit-cost analysis. Telemed J E Health 2009;15(10):933-948.

29. Gagnon MP, Légaré $F$, Labrecque $M$, Frémont $P$, Pluye $P$, Ga- 
gnon J, et al. Interventions for promoting information and communication technologies adoption in healthcare professionals. Cochrane Database Syst Rev 2009;(1):CD006093.

30. Hersh WR, Hickam DH, Severance SM, Dana TL, Krages KP, Helfand M. Telemedicine for the medicare population: update. Evid Rep Technol Assess (Full Rep) 2006;(131):1-41.

31. Drummond MF, Sculpher MJ, Claxton K, Stoddart GL, Torrance GW. Methods for the economic evaluation of health care programmes. 4th ed. Oxford: Oxford University Press; 2015, p. 4244.

32. Drummond MF, Jefferson TO. Guidelines for authors and peer reviewers of economic submissions to the BMJ. The BMJ Economic Evaluation Working Party. BMJ 1996;313(7052):275283.

33. Higgins JP, Green S; Cochrane Collaboration. Cochrane handbook for systematic reviews of interventions. Version 5.1.0: 15.5.2 critical appraisal of methodological quality; 2011 [cited 2016 Jun 6]. Available from: http://handbook.cochrane.org/ chapter_15/15_5_2_critical_appraisal_of_methodological_ quality.htm.

34. Hashimoto S, Shirato H, Kaneko K, Ooshio W, Nishioka T, Miyasaka K. Clinical efficacy of telemedicine in emergency radiotherapy for malignant spinal cord compression. J Digit Imaging 2001;14(3):124-130.

35. Dekio I, Hanada E, Chinuki Y, Akaki T, Kitani M, Shiraishi Y, et al. Usefulness and economic evaluation of ADSL-based live interactive teledermatology in areas with shortage of dermatologists. Int J Dermatol 2010;49(11):1272-1275.

36. Aoki N, Ohta S, Yamamoto H, Kikuchi N, Dunn K. Triangulation analysis of tele-palliative care implementation in a rural community area in Japan. Telemed J E Health 2006;12(6):655-662.

37. Takada A, Kasahara T, Kinosada Y, Hosoba M, Nishimura T. Economic impact of real-time teleradiology in thoracic $\mathrm{CT}$ examinations. Eur Radiol 2003;13(7):1566-1570.

38. Miyahara S, Tsuji M, lizuka C, Hasegawa T, Taoka F. On the evaluation of economic benefits of Japanese telemedicine and factors for its promotion. Telemed J E Health 2006;12(6): 691-697.

39. Tsuji M, Miyahara S, Taoka F, lizuka C, Teshima M. An empirical analysis of economic evaluation of Japanese teleradiology and telepathology. In: Institute of Electrical and Electronics Engineers. Healthcom 2006: Proceedings of 8th International Conference on e-Health Networking, Applications and Services; 2006 Aug 17-19; New Delhi, India. Piscataway: IEEE; 2006, p. $60-65$.
40. Tsuji M, Suzuki W, Taoka F. An economic evaluation of the Japanese telehealth system by CVM: comparison of four regions. In: Institute of Electrical and Electronics Engineers. Healthcom 2003: Proceedings of 5th International Workshop on Enterprise Networking and Computing in Healthcare Industry: 2003 Jun 6-7; Santa Monica, CA, USA. Piscataway: IEEE; 2003; p. 24-28.

41. Tsuji M, Suzuki W, Taoka F. An empirical analysis of a telehealth system in terms of cost-sharing. J Telemed Telecare 2003;9 Suppl 1:S41-S43.

42. Homma S, Sone M, Kurose I, Homma R, Nagare T. Clinical efficacy of a telemedicine program for lifestyle modification involving self-monitoring of health status, and patient compliance with it. Ningen Dock 2012;27(1):97-102.

43. Akematsu Y, Tsuji M. An empirical analysis of the reduction in medical expenditure by e-health users. J Telemed Telecare 2009;15(3):109-111.

44. Akematsu Y, Tsuji M. Measuring the effect of telecare on medical expenditures without bias using the propensity score matching method. Telemed J E Health 2012;18(10):743-747.

45. Akematsu Y, Nitta S, Morita K, Tsuji M. Empirical analysis of the long-term effects of telecare use in Nishi-aizu Town, Fukushima Prefecture, Japan. Technol Health Care 2013;21(2):173182.

46. Ito Y, Suzuki W, Tsuji M, Kamata H, Taoka F, Osaka H. Regional comparative study of home health care: based on a survey on Kamaishi city and Nishiaizu town. Jpn J Med Inform 2003;23 (4):313-323 (Japanese).

47. Osaka $\mathrm{H}$, Kamata $\mathrm{H}$. Influence of user attributes on the effect of home tele-care system. J Iwate Med Assoc 2003;55(5):323331 (Japanese).

48. Tsuji M, Suzuki W, Taoka F, Kamata H, Osaka H, Teshima M. An empirical analysis of the assessment of the tele-home-care system and burden of costs: based on a survey on Kamaishi city. Jpn J Med Inform 2002;22(1):79-86 (Japanese).

49. Tanikawa T, Ohba H, Ogasawara K, Sakurai T. Willingness to pay for the use of tele-consultations in pediatric emergency care. J Jpn Soc Healthcare Admin 2010;47(2):81-91 (Japanese).

50. Fitzpatrick D, Grabarz D, Wang L, Bezjak A, Fehlings MG, Fosker $\mathrm{C}$, et al. How effective is a virtual consultation process in facilitating multidisciplinary decision-making for malignant epidural spinal cord compression? Int J Radiat Oncol Biol Phys 2012;84(2):e167-e172.

51. Chan HH, Woo J, Chan WM, Hjelm M. Teledermatology in Hong Kong: a cost-effective method to provide service to the 
elderly patients living in institutions. Int J Dermatol 2000;39 (10):774-778.

52. Loane MA, Bloomer SE, Corbett R, Eedy DJ, Evans C, Hicks N, et al. A randomized controlled trial assessing the health economics of realtime teledermatology compared with conventional care: an urban versus rural perspective. J Telemed Telecare 2001;7(2):108-118.

53. Loane MA, Bloomer SE, Corbett R, Eedy DJ, Hicks N, Lotery HE, et al. A randomized controlled trial to assess the clinical effectiveness of both realtime and store-and-forward teledermatology compared with conventional care. J Telemed Telecare 2000;6 Suppl 1:S1-S3.

54. Loane MA, Bloomer SE, Corbett R, Eedy DJ, Hicks N, Lotery HE, et al. A comparison of real-time and store-and-forward teledermatology: a cost-benefit study. Br J Dermatol 2000;143(6): 1241-1247.

55. Wootton R, Bloomer SE, Corbett R, Eedy DJ, Hicks N, Lotery $\mathrm{HE}$, et al. Multicentre randomised control trial comparing real time teledermatology with conventional outpatient dermatological care: societal cost-benefit analysis. BMJ 2000;320 (7244):1252-1256.

56. Doolittle GC. A cost measurement study for a home-based telehospice service. J Telemed Telecare 2000;6 Suppl 1:S193S195.

57. Doolittle GC, Whitten P, McCartney M, Cook D, Nazir N. An empirical chart analysis of the suitability of telemedicine for hospice visits. Telemed J E Health 2005;11(1):90-97.

58. Oliver DP, Demiris G, Wittenberg-Lyles E, Washington K, Day T, Novak $\mathrm{H}$. A systematic review of the evidence base for telehospice. Telemed J E Health 2012;18(1):38-47.
59. Hebert MA, Jansen JJ, Brant R, Hailey D, van der Pol M. Successes and challenges in a field-based, multi-method study of home telehealth. J Telemed Telecare 2004;10 Suppl 1:41-44.

60. Bensink ME, Armfield NR, Pinkerton R, Irving H, Hallahan AR, Theodoros DG, et al. Using videotelephony to support paediatric oncology-related palliative care in the home: from abandoned RCT to acceptability study. Palliat Med 2009;23(3):228237.

61. Russell LB, Gold MR, Siegel JE, Daniels N, Weinstein MC. The role of cost-effectiveness analysis in health and medicine. Panel on Cost-Effectiveness in Health and Medicine. JAMA 1996;276(14):1172-1177.

62. Siegel JE, Weinstein MC, Russell LB, Gold MR. Recommendations for reporting cost-effectiveness analyses. Panel on CostEffectiveness in Health and Medicine. JAMA 1996;276(16): 1339-1341.

63. Weinstein MC, Siegel JE, Gold MR, Kamlet MS, Russell LB. Recommendations of the Panel on Cost-effectiveness in Health and Medicine. JAMA 1996;276(15):1253-1258.

64. Yang NH, Dharmar M, Yoo BK, Leigh JP, Kuppermann N, Romano PS, et al. Economic evaluation of pediatric telemedicine consultations to rural emergency departments. Med Decis Making 2015;35(6):773-783.

65. Yoo BK, Kim M, Sasaki T, Melnikow J, Marcin JP. Economic evaluation of telemedicine for patients in ICUs. Crit Care Med 2016;44(2):265-274.

66. Lee CP, Chertow GM, Zenios SA. An empiric estimate of the value of life: updating the renal dialysis cost-effectiveness standard. Value Health 2009;12(1):80-87. 